\title{
FAMILIAL MACULAR COLOBOMATA
}

BY

P. JAMESON EVANS

BIR M INGHAM

THIS report deals with five cases of this condition, four brothers and a sister. The family history originates in the Channel Islands where the maternal grandfather of the affected persons was said to have had defective vision for many years, a somewhat inadequate history but interesting notwithstanding. Of this family several branches are still resident in the Channel Islands and the south of England, and three cases of defective vision are vaguely recalled by members of the family but the opportunity has not yet occurred to examine them. Be that as it may the daughter in question, unfortunately deceased without having been examined ophthalmoscopically, certainly had defective vision from her early days. By her first marriage she had a daughter, who in turn had a son and a daughter. These three present no abnormality of the fundus. In a second venture she married Mr. G. and had four daughters and a

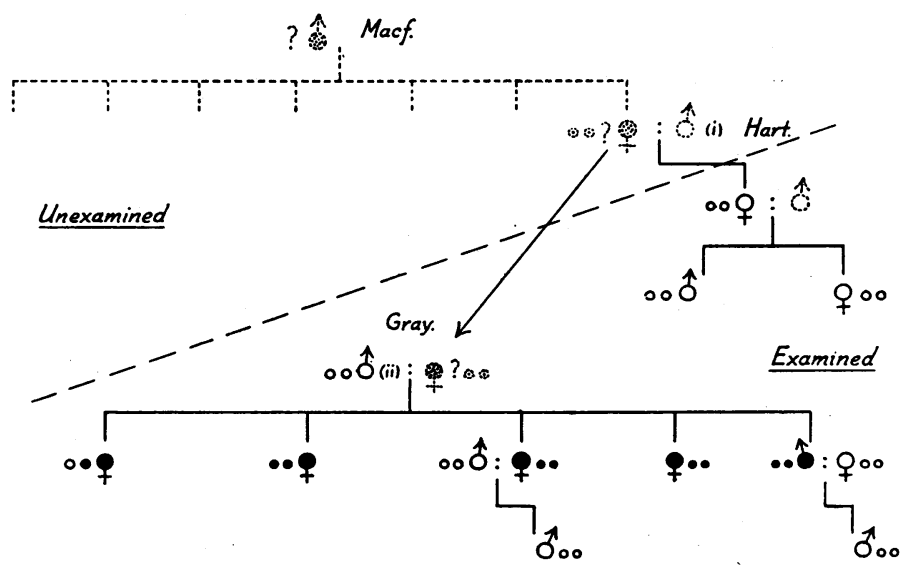

FIG. 1.

Table of family of Gray.

son. Of these the eldest has only a unilateral coloboma while all the others are bilaterally affected. Of the females three are married, but only one has a child, a male, whose fundi are normal. The male member of the family has also an infant son, who presents no abnormality.

The whole subject of macular coloboma has been admirably and recently reviewed bv Sorsby so it will be enough to state briefly the actual findings in the family now under discussion :- 
J.W. G. Father: normal maculae, vision $6 / 12$ in each eye without glasses. Some retinal arteriosclerosis was present and there was oedema of the lower lids and ankles. He died in 1934, aged 76 years, from cardiac failure, leaving four daughters and a son.

(i) Mrs. A. P., aged 56 years. Has never noticed any defect of vision. Vision $6 / 6$ in each eye without glasses. Refractive error small degree of myopia. The left fundus is normal; the right shows a typical macular coloboma about $1 \frac{1}{2}$ D.D. in horizontal extent and about one disc diameter vertically. The fovea would appear to be placed towards the inner limit of the coloboma. No other ocular abnormality was found. She has had no children.

(ii) Mrs. C. W., aged 51 years. Has had defective vision since childhood.

$$
\begin{aligned}
& \text { Vision: Right } 6 / 36 \bar{c}+1 \cdot 25 \\
& +4.50 \rightarrow 180 \\
& \text { Left } 6 / 18 \bar{c}+\frac{1 \cdot 75}{+3 \cdot 0 \rightarrow 180}
\end{aligned}
$$

The patient shows a slight rotary nystagmus. There is bilateral macular coloboma measuring about $1 \frac{1}{2} \times 1$. D.D. in each eye, the long axis horizontal. On examination on the Gullstrand ophthalmoscope the coloboma is seen to consist of a sharply excavated

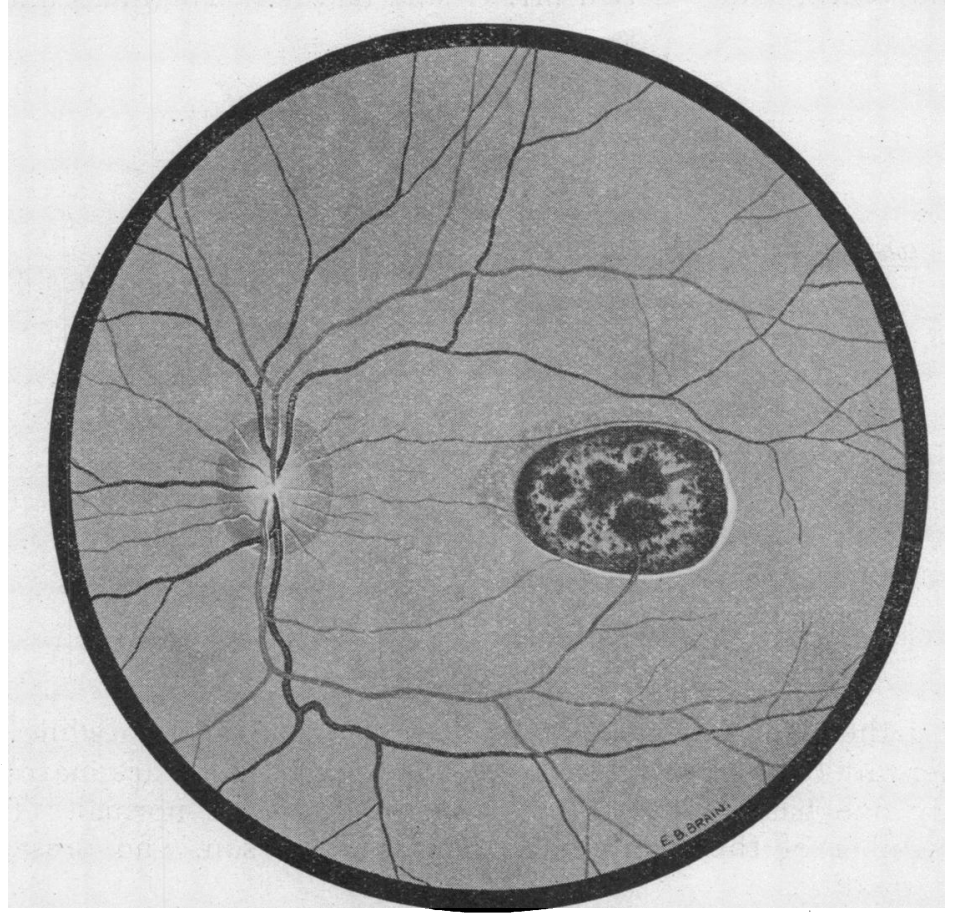

Fig 2.

Drawing of left fundus. (C. W.) 
area, the actual edge of the retina slightly shelving. In the centre of the degenerated area the black pigmented masses are slightly raised. No retinal vessels are seen running over the coloboma but small arterioles appear to dip into it. The excavated area is not so pigmented in its peripheral parts but there is further pigment in excess immediately surrounding the hole. Her husband, and son (aged 17 years), present no abnormality.

(iii) Mrs. B., aged 46 years, realised her vision was poor when very young.

$$
\text { Vision: Right } 6 / 12 \bar{c}-2 \cdot 0 \text { Left } 6 / 36 \overline{\mathrm{c}}-2 \cdot 0
$$

The patient presents an almost identical fundus picture with that of the previous sister, except that in both eyes the coloboma is rather larger, measuring about $2 \times 1 \frac{1}{2}$ disc diameter in each eye. In other respects the eyes appeared normal. She has no children.

(iv) Miss $G$., aged 42 years, discovered her visual defect at the age of eight.

$$
\text { Vision : Right } \overline{\mathrm{c}}-1.50=6 / 60 \text { Left } \overline{\mathrm{c}}-1.50=6 / 36
$$

She has a divergent strabismus of the right eye of $20^{\circ}$. She shows bilateral macular colobomata, measuring some $2 \frac{1}{2} \times 2$ disc diameters, and the fovea appears to be close to the centre of the coloboma in each instance.

(v) J.W.G., aged 39 years, the only brother, has known of his defective sight since childhood.

$$
\begin{aligned}
& \text { Vision : } \text { Right } \bar{c} \frac{-3 \cdot 50}{+2.0} \rightarrow 180=6 / 36 \\
& \text { Left } \bar{c} \frac{-4 \cdot 25}{+0.75} \rightarrow 180=6 / 18
\end{aligned}
$$

He shows bilateral colobomata but apart from this no abnormality. The coloboma in the right eye is diffusely pigmented by black interlacing strands which completely fill the excavation, but in the left eye the pigmentation is chiefly limited to the outer third of the hole. The position of the colobomata is such that the fovea would be involved in each eye. Vision in the left eye is good enough to permit of reading and for the patient to have become a clergyman. $\mathrm{His}$ wife, and son (aged two years), have normal fundi.

(vi) Mrs. G., the mother, appears to have had bad sight for most of her life but died before this investigation was initiated. By her first marriage she had one daughter, whose eyes are normal. The latter in turn has a son and a daughter who present no abnormality. For this information I am indebted to Dr. Thompson and Dr. Starlberg. Unfortunately it has been impossible as yet to seek out the other members of the families in the Channel Islands but it is hoped to do so at a later date.

In this family no other physical defects of the limbs, etc., have been found and, apart from the ocular conditions, all these persons are normal. 


\title{
Summary
}

The condition of familial macular coloboma is found in five members of a family.

The next generation so far shows no similar defects. The previous generation unfortunately cannot be fully investigated but the suggestion is that the defect in this family derives from the maternal side. Further observations in the side branches on this side of the family may possibly provide instances of the same defect.

\section{EYELASH IN THE ANTERIOR CHAMBER FOLLOWING THE REMOVAL OF AN INTRA-OCULAR FOREIGN BODY}

BY

\author{
W. J. B. RIDDELI
}

GLASGOW

THE interest of this case lies in the possibility that the eyelash entered the eye after the removal of an intra-ocular foreign body. The patient was a man aged 19 years, who received what he assumed to be a trivial injury to his left eye at his work in July, 1936. Shortly after the accident he went on holiday and discovered that the vision in the eye was failing. I saw him early in August, 1936, for the first time. The right eye was normal and has remained so. The left eye was white and showed no sign of inflammation and was not injected. In the central area of the cornea there was a small healed punctured wound. The anterior chamber was of normal depth, the pupil was active and the iris showed no sign of injury. A traumatic cataract was present and in the lens substance a small metallic foreign body was seen. The vision was reduced to hand movements. He had no pain and regarded the injury as trivial until he noticed the sight failing.

On August 12, 1936, the foreign body was removed through a straight keratome section by means of a hand magnet. A guarded speculum was used and no instrument entered the eye except the straight keratome. Before the section was made the foreign body was brought forward through the lens substance but could not be got into the anterior chamber because the wound in the lens capsule had sealed. Consequently a small opening in the capsule was made with the point of the keratome before withdrawal. 'This opening was several millimetres below the section and no capsule was drawn up. The section was made without loss 